\title{
Activation of Mo and V oxides supported on ZSM-5 zeolite catalysts followed by in situ XAS and XRD and their uses in oxydehydration of glycerol
}

\author{
Luiz G. Possato ${ }^{\mathrm{a}, *}$, Mauro D. Acevedo ${ }^{\mathrm{b}}$, Cristina L. Padróc, Valérie Briois ${ }^{\mathrm{d}}$, Aline R. Passos ${ }^{\mathrm{a}, \mathrm{d}}$, \\ Sandra H. Pulcinelli ${ }^{\mathrm{a}}$, Celso V. Santilli ${ }^{\mathrm{a}}$, Leandro Martins ${ }^{\mathrm{a}}$ \\ ${ }^{a}$ Universidade Estadual Paulista (UNESP), Instituto de Química, Campus de Araraquara, Rua Prof. Francisco Degni 55, 14800-060 Araraquara, SP, Brazil \\ ${ }^{\mathrm{b}}$ Universidad Nacional del Chaco Austral, Comandante Fernández 755, CP 3700, Pcia. Roque Sáenz Peña, Chaco, Argentina \\ ${ }^{c}$ Catalysis Science and Engineering Research Group (GICIC), INCAPE (UNL-CONICET), Predio CCT Conicet, Paraje El Pozo, (3000) Santa Fe, Argentina \\ d Synchrotron SOLEIL, L'Orme des Merisiers, BP48, Saint Aubin, 91192 Gif-sur Yvette, France
}

\section{A R T I C L E I N F O}

\section{Keywords:}

Time-resolved XAS

Mixed oxides

Zeolite

Glycerol

Acrylic acid

\begin{abstract}
A B S T R A C T
This paper describes the activation and catalytic performance of a multifunctional catalyst consisting of mixed oxides of vanadium and molybdenum supported on an acidic ZSM-5 zeolite. The zeolite was wet-impregnated with an aqueous solution containing a mixture of $\mathrm{NH}_{4} \mathrm{VO}_{3}$ and $\left(\mathrm{NH}_{4}\right)_{6} \mathrm{Mo}_{7} \mathrm{O}_{24}$ precursors at a V/(Mo $\left.+\mathrm{V}\right) \mathrm{molar}$ ratio of 0.6 . Evolution of the phases during activation (by calcination under $20 \% \mathrm{O}_{2} / \mathrm{He}$ ) was followed by synchrotron X-ray diffraction (XRD), but detection of mixed oxides of $\mathrm{Mo}_{\mathrm{x}} \mathrm{V}_{\mathrm{y}} \mathrm{O}_{\mathrm{z}}$ was difficult, due to the high degree of dispersion on the zeolite surface. On the other hand, X-ray absorption spectroscopy (XAS) performed simultaneously at the Mo and V K-edges enabled confirmation of formation of the $\mathrm{MoV}_{2} \mathrm{O}_{8}$ phase on the acidic ZSM-5 zeolite. The combination of the $\mathrm{MoV}_{2} \mathrm{O}_{8}$ phase and the zeolite acid sites produced a highly active catalyst for gas phase glycerol dehydration-oxidation coupled reactions in which acrylic acid was the main product. The multifunctional catalyst presented only $6 \%$ of deactivation during a period of $8 \mathrm{~h}$ under glycerol stream, while the activities of the bulk mixed oxide and the pure ZSM-5 zeolite decreased by almost 20 and 31\%, respectively.
\end{abstract}

\section{Introduction}

The depletion of non-renewable energy feedstocks, together with their environmental impacts, has motivated the search for eco-friendly alternatives to substitute fuels produced by the petrochemical industry. The development of green processes to obtain compounds such as acrolein and acrylic acid from glycerol has attracted much attention globally, due to the co-production of glycerol in the transesterification reactions of vegetable oils [1-9].

Glycerol dehydration-oxidation reactions for the formation of acrylic acid occur in two steps (Scheme 1). The first step involves the double dehydration of glycerol on acid sites, with 3-hydroxypropanal and acrolein as the first and second intermediates, respectively. In this step, there is a relation between the Brønsted acid sites of the catalyst and the formation of acrolein [9], as observed for niobium catalysts by Foo et al. [10]. Glycerol is also dehydrated to acetol at Lewis acid sites, with a linear correlation having been observed between the concentration of Lewis acid sites and acetol production [10]. In another study performed with zeolites, a cooperative effect between Brønsted and Lewis acid sites was suggested to provide high acrolein selectivity
[11]. In any case, the formation of acrolein is favoured on catalysts containing Brønsted acid sites.

The second step is the oxidation of acrolein to acrylic acid. In order for these reactions to occur in a single catalytic bed, it is necessary to use bifunctional catalysts that possess acid and oxidative properties [12-14]. For instance, vanadium oxides supported on highly acidic zeolites, or bare mixed oxides (of $\mathrm{Co}, \mathrm{Fe}, \mathrm{V}$, Mo, or W) possessing both acid and oxidative sites [15-19], have been successfully used in gas phase reactions for glycerol conversion [20-24]. In the case of W-Nb-O catalysts, only acrolein is produced, while acrylic acid is also produced when W-Nb-V-O catalysts are used [25]. According to Omata et al. [25], there is a relation between the Brønsted acid sites and the concentration of vanadium in $\mathrm{W}-\mathrm{Nb}-\mathrm{V}-\mathrm{O}$ catalysts that can be exploited in order to provide high selectivity to acrylic acid, under a suitable oxidizing atmosphere.

The use of oxides of vanadium and molybdenum in this reaction has been highlighted due to the versatility of the formation of crystalline or amorphous phases in the course of the reaction, with the redox cycle of the active sites providing effective oxidation of acrolein to acrylic acid [15-17]. A major problem concerning the bare mixed oxides of

\footnotetext{
* Corresponding authors.

E-mail address: gustavo.possato@unesp.br (L.G. Possato).
} 


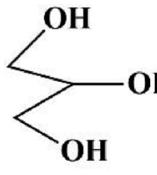

Glycerol

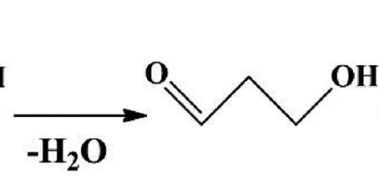

3-hydroxypropanal

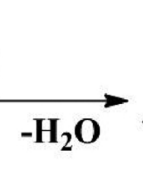

Acrolein

Scheme 1. Coupled dehydration-oxidation of glycerol.

vanadium and molybdenum is their low acidity, because high acidity is essential in the first dehydration step. Zeolites are good candidates for use in the reaction, since they possess strong Brønsted acid sites. However, the main drawback of pure zeolites is that there is the formation of not only acrolein, but also heavier polymeric compounds such as polyaromatics and/or polyglycols [26].

In a publication of 2015 [26], it was shown that $\mathrm{V}_{2} \mathrm{O}_{5}$ supported on acidic ZSM- 5 zeolite provided a combination of acid and oxidizing sites that made it possible to produce acrylic acid in a single step, without significant formation of deactivating carbonaceous residues. The explanation for the observed resistance against deactivation was based on the proximity of the acid and redox active sites, which enabled continuous oxidation of undesired monomeric coke residues, prior to their polymerization. Furthermore, an optimal thermal balance was provided by coupling of the exothermic acrolein oxidation with the endothermic dehydration.

More recently [27], it was shown that pure mixed oxides of $\mathrm{Mo}_{\mathrm{x}} \mathrm{V}_{\mathrm{y}} \mathrm{O}_{\mathrm{z}}$ were 3.5 times more active than the single metal oxides $\mathrm{V}_{2} \mathrm{O}_{5}$ and $\mathrm{MoO}_{3}$, because the structure of the mixed oxide affected the nearby metal valence of vanadium. As a result, dynamic changes in the oxidation state of the metal during the catalytic reaction created spontaneous oxygen vacancies that participated in the reaction by supplying oxygen atoms for the oxidation of acrolein.

This study contributes to understanding the dehydration-oxidation reactions of glycerol to produce acrylic acid, by exploring the combined catalytic activity of two important catalysts for this reaction: mixed $\mathrm{Mo}_{\mathrm{x}} \mathrm{V}_{\mathrm{y}} \mathrm{O}_{\mathrm{z}}$ oxides supported on acidic ZSM-5 zeolite. During the activation step, consisting of oxidative thermal treatment of the impregnated precursors, time-resolved synchrotron radiation X-ray diffraction and Xray absorption measurements were performed in order to elucidate the structures of the active species formed using the different catalysts. The catalytic activities of the materials in the formation of acrylic acid were evaluated, together with their long-term stabilities. Finally, the formation of coke responsible for deactivation was studied for the different spent catalysts.

\section{Experimental}

\subsection{Preparation of catalysts}

The ZSM-5 zeolite in ammonium form $\left(\mathrm{NH}_{4}{ }^{+}\right.$-ZSM-5, with Si/Al molar ratio of 40) was kindly provided by Zeolyst. The Mo-V-ZSM-5 catalyst was obtained by simultaneous wet impregnation in aqueous solutions of $\mathrm{NH}_{4} \mathrm{VO}_{3}$ and $\left(\mathrm{NH}_{4}\right)_{6} \mathrm{Mo}_{7} \mathrm{O}_{24}(0.05 \mathrm{~mol} / \mathrm{L})$, maintaining a $\mathrm{Mo} /(\mathrm{Mo}+\mathrm{V})$ molar ratio of 0.6 , as described in a previous study [27]. The volumes of the solutions containing the precursors were calculated in order to obtain a $(\mathrm{Mo}+\mathrm{V}) / \mathrm{Al}$ molar ratio of 5.5 ( $\mathrm{Al}$ stands for zeolite framework aluminium). The mixtures were stirred at room temperature for $1 \mathrm{~h}$, followed by evaporation of the water in a rotary evaporator. The dry material was calcined at $500{ }^{\circ} \mathrm{C}$ (with heating at $10{ }^{\circ} \mathrm{C} / \mathrm{min}$ ) for $2 \mathrm{~h}$, under a flow of air, resulting in the $\mathrm{Mo}_{\mathrm{x}} \mathrm{V}_{\mathrm{y}} \mathrm{O}_{\mathrm{z}} / \mathrm{H}^{+}$-ZSM-5 catalyst (denoted Mo-V-ZSM-5). Vanadium oxide and molybdenum oxide supported on the zeolite (V-ZSM-5 and Mo-ZSM-5, respectively) were also prepared using a metal/Al ratio of 5.5. Bulk unsupported $\mathrm{Mo}_{\mathrm{x}} \mathrm{V}_{\mathrm{y}} \mathrm{O}_{\mathrm{z}}$ mixed oxide was prepared as described previously [27], using a $\mathrm{Mo} /(\mathrm{Mo}+\mathrm{V})$ molar ratio of 0.6 .

\subsection{Characterization of the catalysts}

The crystalline phases of the calcined samples were identified from powder X-ray diffractograms acquired using a Siemens D5000 diffractometer, with $\mathrm{Cu}-\mathrm{K} \alpha$ radiation selected by a curved graphite monochromator. Data were collected in the $2 \theta$ range from $7^{\circ}$ to $60^{\circ}$, with a scan step of $0.01^{\circ}$ and counting time of $4 \mathrm{~s}$ per step.

In situ powder X-ray diffraction analysis was carried out during heating of the Mo-V-ZSM- 5 precursor under a flow of $20 \% \mathrm{O}_{2}$ in $\mathrm{He}$, at the XPD beamline of the Brazilian Synchrotron Light Laboratory (LNLS). The XPD beamline had a Huber $4+2$-circle diffractometer equipped with an Eulerian cradle (Model 513), positioned around $13 \mathrm{~m}$ from the double-bounce $\mathrm{Si}(111)$ monochromator $(\lambda=0.1377 \mathrm{~nm})$ [28]. Data were collected in high resolution mode, employing a Si(111) analyzer crystal and a Mythen detector. The thermal treatment was performed from room temperature up to $500{ }^{\circ} \mathrm{C}$, with a heating rate of $5{ }^{\circ} \mathrm{C} / \mathrm{min}$, under a $60 \mathrm{ml} / \mathrm{min}$ flow $\mathrm{O}_{2}$ in He. Each diffraction pattern was obtained in the $2 \theta$ range from 20 to $30^{\circ}$, and required $2 \mathrm{~min}$. A wide range scan from 7 to $60^{\circ}$ should be used for a more precise phase analysis. However, the use of a heating ramp of $5{ }^{\circ} \mathrm{C} / \mathrm{min}$ made it impossible to achieve sufficiently high time resolution to follow the transitions between the crystalline phases. Previous scans of a few regions indicated that the $2 \theta$ range from 20 to $30^{\circ}$ was most appropriate for providing a satisfactory compromise between the quality of the refinement and the number of acquired scans.

${ }^{27} \mathrm{Al} \mathrm{NMR}$ spectra of the zeolites were acquired using a Varian INOVA 500 spectrometer equipped with a $7 \mathrm{~mm}$ probe and operated at $4.5 \mathrm{kHz}$. The experiments were performed using a spinning rate of $78.2 \mathrm{MHz}$, acquisition time of $15.4 \mathrm{~ms}$, pulse width of $2.4 \mu \mathrm{s}$, and recycle delay of $0.1 \mathrm{~s}$. The ${ }^{27} \mathrm{Al}$ chemical shifts were referenced to an aqueous solution of $\mathrm{Al}\left(\mathrm{NO}_{3}\right)_{3}(1 \mathrm{~mol} / \mathrm{L})$. Each spectrum was the result of 256 scans.

X-ray absorption spectra at the vanadium $(5465 \mathrm{eV})$ and molybdenum (20 keV) K-edges were obtained simultaneously during calcination of the catalyst precursors, using the edge jumping capability of the Quick-EXAFS ROCK beamline at the French SOLEIL synchrotron [29]. $\mathrm{Si}(111)$ and $\mathrm{Si}(220)$ channel-cut crystals were used alternately as monochromators for the $\mathrm{V}$ and Mo K-edges, respectively. For each edge, a frequency of $2 \mathrm{~Hz}$ was selected for the crystal oscillation (amplitudes of $3.9^{\circ}$ for the $\mathrm{Si}(111)$ channel-cut and $0.9^{\circ}$ for the $\mathrm{Si}(220)$ channel-cut), allowing the acquisition of two spectra, each of $0.25 \mathrm{~s}$ (one with increasing energy and the other with decreasing energy). Consecutive spectra (obtained with decreasing energy) saved during $35 \mathrm{~s}$ at each edge were merged in order to improve the signal/noise ratio. The experiments consisted of in situ decomposition of the supported vanadium and molybdenum precursors during heating from room temperature to $500{ }^{\circ} \mathrm{C}$, at $10^{\circ} \mathrm{C} / \mathrm{min}$, under a flow of $\mathrm{He} / \mathrm{O}_{2}$ (gas ratio of $20 / 80$ ). The decomposition products formed during the calcination were also monitored using an on-line quadrupole mass spectrometer (Cirrus, MKS) connected to the cell by a $2 \mathrm{~m}$ heated silicon capillary tube. Considering the heating rate of $10{ }^{\circ} \mathrm{C} / \mathrm{min}$ and the times for data collection and for jumping from one edge to the other, the temperature difference between successive measurements at a given edge was about $25^{\circ} \mathrm{C}$. The mass spectrometry monitoring evidenced the formation and evolution of reaction products within a shorter temperature range, so it was decided to repeat the quick-EXAFS monitoring at the Mo K-edge, with no jump at the $\mathrm{V}$ K-edge, in order to obtain a finer description of 
the evolution of the species. The speciation of each metal was determined using multivariate curve regression with alternating least square minimization (MCR-ALS). Details about the use of the MCR-ALS method applied to XAS can be found in recent papers [30-33] and in the Supporting Information. The absorption spectra were analyzed using the Athena and Artemis graphical interface software packages [34]. For the Mo K-edge, the $\mathrm{k}^{3} \chi(\mathrm{k})$ data were Fourier-transformed between 4.6 and $14.5 \AA^{-1}$, using a Kaiser-Bessel window with a dk of 2 . To fit the EXAFS data, the initial values of $E_{0}$, used for k-scaling, and $S_{0}{ }^{2}$, the amplitude reduction factor, were obtained by fitting the EXAFS results for the crystalline $\mathrm{MoO}_{3}$ reference, with the number of nearest neighbour atoms $(N)$ and their distance $(R)$ fixed at their expected crystallographic values [35]. The values obtained $\left(E_{0}\right.$ of $20015.5 \pm 2.7 \mathrm{eV}$ and $\mathrm{S}_{0}{ }^{2}$ of 0.74 ) were then used for modelling of the EXAFS signals for the intermediate phase obtained during calcination of the Mo-V-ZSM-5 catalyst. The fit quality was determined using the EXAFS reliability factor, $R_{\mathrm{F}}$, which measures the relative misfit with respect to the experimental data.

The acid sites of the calcined catalysts were determined by temperature-programmed desorption of ammonia (TPD- $\mathrm{NH}_{3}$ ). A $200 \mathrm{mg}$ portion of each sample was previously degassed at $300^{\circ} \mathrm{C}$ for $1 \mathrm{~h}$, under a $60 \mathrm{ml} / \mathrm{min}$ flow of He. The temperature was then decreased to $100^{\circ} \mathrm{C}$ and the sample was exposed for $1 \mathrm{~h}$ to a flow of $1 \%$ ammonia in $\mathrm{He}$ $(60 \mathrm{~mL} / \mathrm{min})$. After surface saturation, the physisorbed ammonia was removed at $100^{\circ} \mathrm{C}$ for $1 \mathrm{~h}$, under a flow of He. The TPD-NH $\mathrm{N}_{3}$ analysis was performed from 100 to $600{ }^{\circ} \mathrm{C}$ (at $10^{\circ} \mathrm{C} / \mathrm{min}$ ), under a $60 \mathrm{ml} / \mathrm{min}$ flow of He. The desorbed ammonia was monitored and quantified using a Pfeiffer vacuum mass spectrometer connected to the outlet stream of the tubular reactor.

The nature of the surface acid sites was determined by Fourier transform infrared spectroscopy (FTIR), using a Shimadzu Prestige-21 spectrophotometer and pyridine as the probe molecule. The samples ( $\sim 20 \mathrm{mg}$ ) were pressed into thin disks (using a pressure force of 2 ton/ $\mathrm{cm}^{2}$ ) with diameters of approximately $13 \mathrm{~mm}$. Before pyridine adsorption, all the samples were pre-treated in an all-glass vacuum system at $450{ }^{\circ} \mathrm{C}$, for $60 \mathrm{~min}$, under a pressure of $0.013 \mathrm{~Pa}$. For the adsorption experiments, the samples were cooled to $25^{\circ} \mathrm{C}$, under vacuum, followed by injection of $2 \mu \mathrm{L}$ of liquid pyridine. The spectra were obtained as the average of 40 runs, at room temperature, after admission of pyridine, adsorption at room temperature, and sequential evacuation at 25, 150, and $300{ }^{\circ} \mathrm{C}$. A resolution of $4 \mathrm{~cm}^{-1}$ was used in all the experiments. The background spectrum was recorded under identical operating conditions, without sample, and was automatically subtracted. The relative concentrations of Brønsted and Lewis acid sites were calculated from the intensities of the $\mathrm{PyH}^{+}$and $\mathrm{PyL}$ bands (at around 1545 and $1450 \mathrm{~cm}^{-1}$, respectively) and using the Emeis molar extinction factor [36].

The textural properties of the supports and the impregnated catalysts were determined by means of nitrogen adsorption-desorption isotherms obtained at $-196{ }^{\circ} \mathrm{C}$ with a Micromeritics ASAP 2010 instrument, using a relative pressure $\left(\mathrm{P} / \mathrm{P}_{0}\right)$ interval of $0.001-0.998$. The samples were previously decontaminated by degassing for $12 \mathrm{~h}$, at $100{ }^{\circ} \mathrm{C}$, under a vacuum of $1 \times 10^{-5} \mathrm{~Pa}$.

Temperature-programmed reduction (TPR) experiments were performed using a Micromeritics AutoChem II 2920 system equipped with a thermal conductivity detector. The tests employed a $5 \% \mathrm{H}_{2} / \mathrm{Ar}$ mixture $(50 \mathrm{~mL} / \mathrm{min}), 250 \mathrm{mg}$ of sample, and a heating ramp of $10^{\circ} \mathrm{C} / \mathrm{min}$ in the temperature range $25-650^{\circ} \mathrm{C}$. Since water was formed during sample reduction, the gas exiting from the reactor was passed through a cold trap before entering the thermal conductivity detector.

\subsection{Catalytic reaction}

The glycerol dehydration-oxidation reactions were performed at $320^{\circ} \mathrm{C}$ and atmospheric pressure, using $200 \mathrm{mg}$ of finely divided catalyst powder deposited on a fixed bed inside a glass reactor. The reaction temperature was monitored using a thermocouple placed in contact with the catalytic bed. The sample was first heated to the reaction temperature, under a mixed flow of $\mathrm{N}_{2}$ and $\mathrm{O}_{2}$ (at 24 and $6 \mathrm{~mL} / \mathrm{min}$, respectively), and was kept at this temperature for $15 \mathrm{~min}$. A solution of $10 \mathrm{wt} . \%$ of glycerol (99\%, Sigma-Aldrich) in water was continuously introduced at $0.05 \mathrm{~mL} / \mathrm{min}$, using a syringe pump (KD Scientific), and was vaporized to the gas line. The space velocity was $5 \mathrm{~h}^{-1}$. The products leaving the reactor were collected in a gas-liquid separator kept at $1{ }^{\circ} \mathrm{C}$ and were analysed using a Shimadzu GC-2014 gas chromatograph equipped with a capillary column (Rtx-1, length of $30 \mathrm{~m}$, ID of $0.32 \mathrm{~mm}$, film thickness of $1 \mu \mathrm{m}$ ) and a FID detector. The gas-liquid separator was kept at a low temperature, in order to ensure complete condensation of the most volatile compound (acetaldehyde, b.p. $20^{\circ} \mathrm{C}$ ). Before each injection, a known mass of n-butanol was added as an internal standard, in order to be able to perform a quantitative mass balance for the condensed products. The analyses were carried out in triplicate and the retention times were compared to those of authentic compounds. The glycerol conversion $\left(\mathrm{X}_{\text {glycerol }}\right)$ and products selectivity (S) were calculated according to Eqs. (1) and (2):

$X_{\text {glycerol }}(\%)=\frac{n_{G l}^{\text {input }}-n_{G l}^{\text {output }}}{n_{G l}^{\text {input }}} \times 100$

$S_{i}(\%)=\frac{n_{i}}{n_{G l}^{\text {input }}-n_{G l}^{\text {output }}} \times 100$

where $n_{G l}^{\text {input }}$ and $n_{G l}{ }^{\text {output }}$ are the molar flows of glycerol in the input and output; $n_{i}$ is the molar flow of products $i$; and $Z_{G l}=3$ and $Z_{i}$ represent the numbers of carbon atoms in the molecules of glycerol and the products, respectively.

\section{Results and discussion}

\subsection{Characterization of the impregnated zeolites}

The powder X-ray diffraction patterns of the ZSM- 5 zeolite and the bifunctional catalysts are shown in Fig. 1. Notably, the main reflections related to crystallographic planes (001), (200), and (051) of the zeolites were maintained after impregnation and calcination. The calcined MoZSM-5 sample (Fig. 1c) presented a reflection additional to that of the ZSM-5 zeolite (Fig. 1a), which is attributed to the $\mathrm{MoO}_{3}$ (040) plane.

The diffractogram for the Mo-V-ZSM-5 catalyst (Fig. 1e) did not present clear reflections for mixed oxides such as the active $\mathrm{MoV}_{2} \mathrm{O}_{8}$ phase reported for unsupported Mo-V-O catalysts [20], or for simple oxides such as $\mathrm{MoO}_{3}$ and $\mathrm{V}_{2} \mathrm{O}_{5}$. In an attempt to evaluate the formation of intermediates, X-ray diffractograms were acquired in situ during heat treatment of the impregnated sample (Fig. 1f). In the previous study of unsupported mixed oxides of Mo and V, it was shown that several intermediate mixed oxides were formed during the heat treatment, with orthorhombic $\mathrm{MoV}_{2} \mathrm{O}_{8}$ being the most abundant structure obtained at $500{ }^{\circ} \mathrm{C}$ (61 wt.\%; Table 1) [27]. The main reflections of $\mathrm{MoV}_{2} \mathrm{O}_{8}$ corresponding to the (001), (021), and (600) crystallographic planes are located in the $2 \theta$ region between 21 and $28^{\circ}$. However, due to either a high degree of dispersion and/or the presence of amorphous Mo-V oxide counterparts, no diffraction peaks characteristic of the molybdenum/vanadium oxides were observed for the Mo-V-ZSM-5 catalyst in the in situ XRD study. Quantitative phase analysis using the Rietveld method applied to the full X-ray diffraction patterns of the calcined catalysts showed only $1 \%$ of the mixed $\mathrm{MoV}_{2} \mathrm{O}_{8}$ oxide in the Mo-V-ZSM-5 sample (Table 1), which was within the accuracy range of the refinement. In addition, at high temperature $\left(500^{\circ} \mathrm{C}\right)$, observations of vanadium/molybdenum peaks are challenging, due to the DebyeWaller effect.

Another feature of the X-ray diffraction analyses was the decreased intensities of the reflections for the impregnated zeolites. The ${ }^{27} \mathrm{Al} \mathrm{NMR}$ spectra (Fig. 2) showed that in addition to the signal for the tetrahedral aluminium atom of the zeolite framework at $54 \mathrm{ppm}$, signals for extra- 

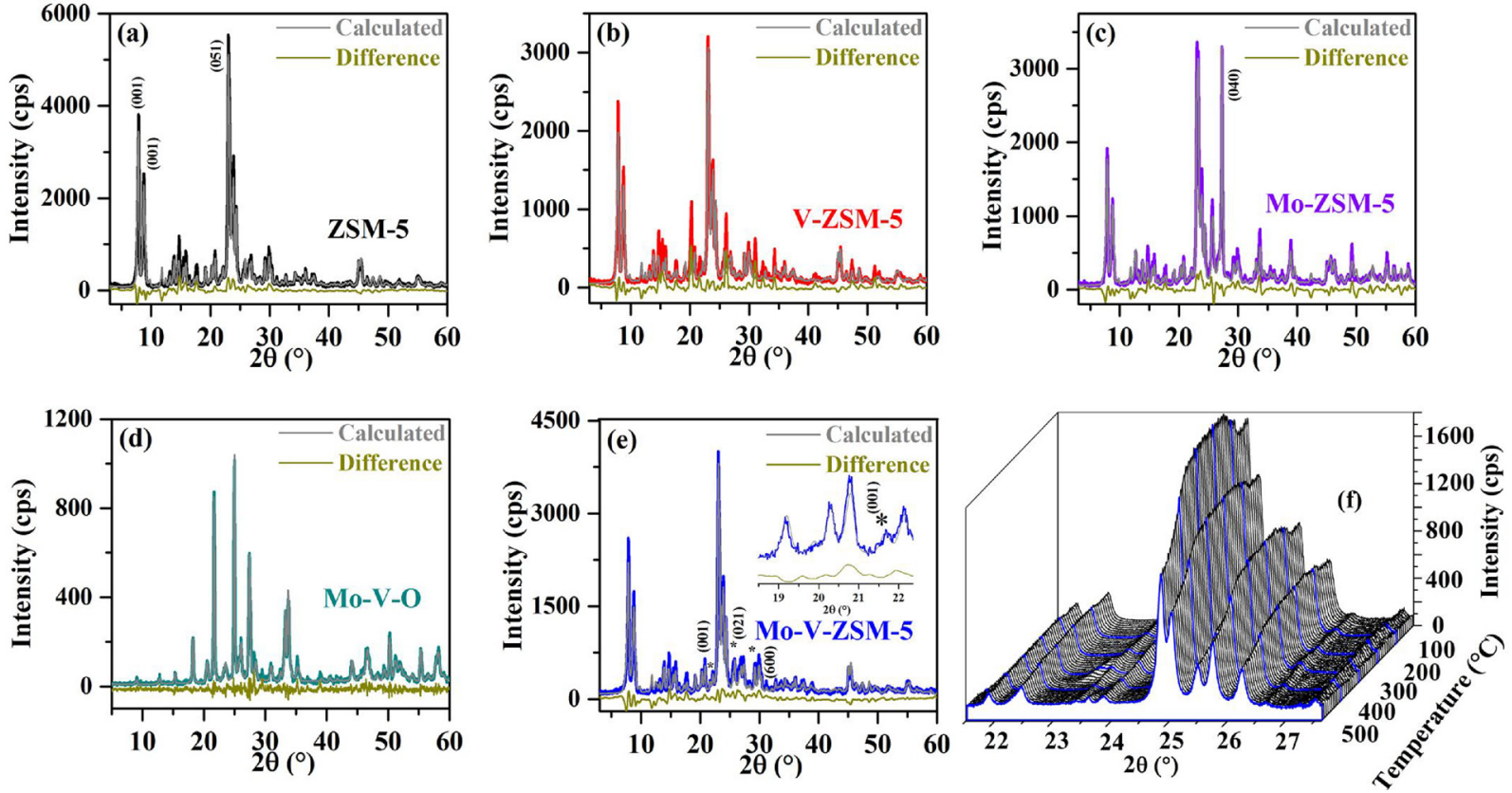

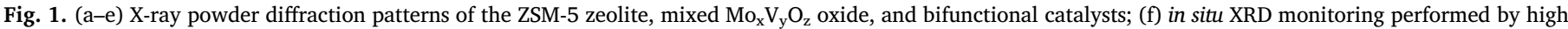
resolution X-ray diffraction during calcination of the precursor of Mo-V-ZSM-5.

Table 1

Crystalline phase speciation (wt.\%) determined by quantitative phase analysis of pristine ZSM-5, the mixed $\mathrm{Mo}_{\mathrm{x}} \mathrm{V}_{\mathrm{y}} \mathrm{O}_{\mathrm{z}}$ oxide, and the impregnated catalysts.

\begin{tabular}{lllll}
\hline Catalyst & ZSM-5 (\%) & $\mathrm{V}_{2} \mathrm{O}_{5}(\%)$ & $\mathrm{MoO}_{3}(\%)$ & $\mathrm{MoV}_{2} \mathrm{O}_{8}(\%)$ \\
\hline ZSM-5 & 100 & 0 & 0 & 0 \\
V-ZSM-5 & 100 & 0 & 0 & 0 \\
Mo-ZSM-5 & 76.5 & 0 & 23.5 & 0 \\
Mo-V-ZSM-5 & 94.7 & 0 & 4.3 & 1.0 \\
Mo-V-O (bulk) $^{\mathrm{a}}$ & 0 & 9.2 & 29.8 & 61.0 \\
\hline
\end{tabular}

a Composition of the fresh catalyst. After the use in the catalytic conversion of glycerol, the phase composition was as follows: $5.0 \% \mathrm{~V}_{2} \mathrm{O}_{5}, 24.6 \% \mathrm{MoO}_{3}$, 7.5\% $\mathrm{MoV}_{2} \mathrm{O}_{8}$, and 62.9\% $\mathrm{Mo}_{4} \mathrm{~V}_{6} \mathrm{O}_{25}$ [27].

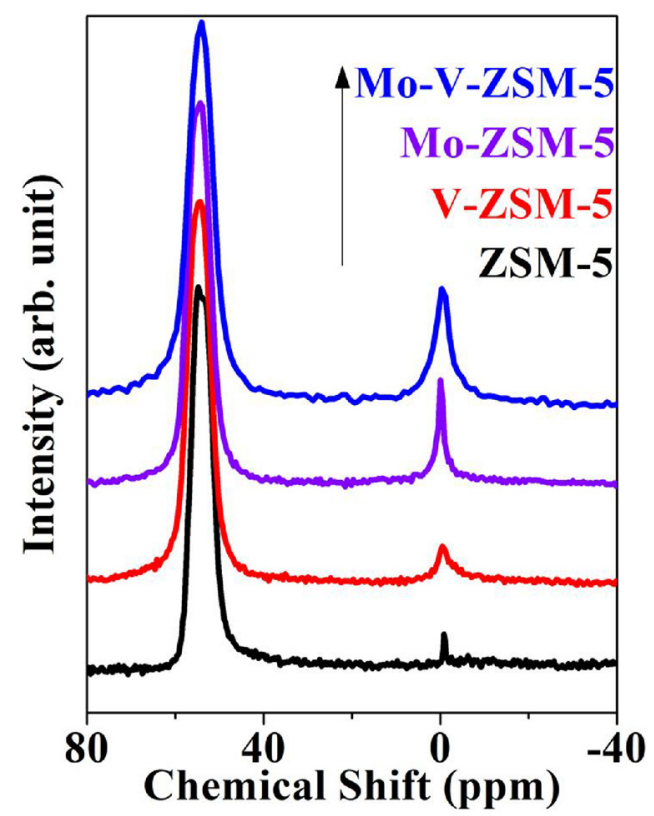

Fig. 2. ${ }^{27} \mathrm{Al}$ NMR spectra of the ZSM-5 zeolite, before and after impregnation with molybdenum and vanadium oxides.

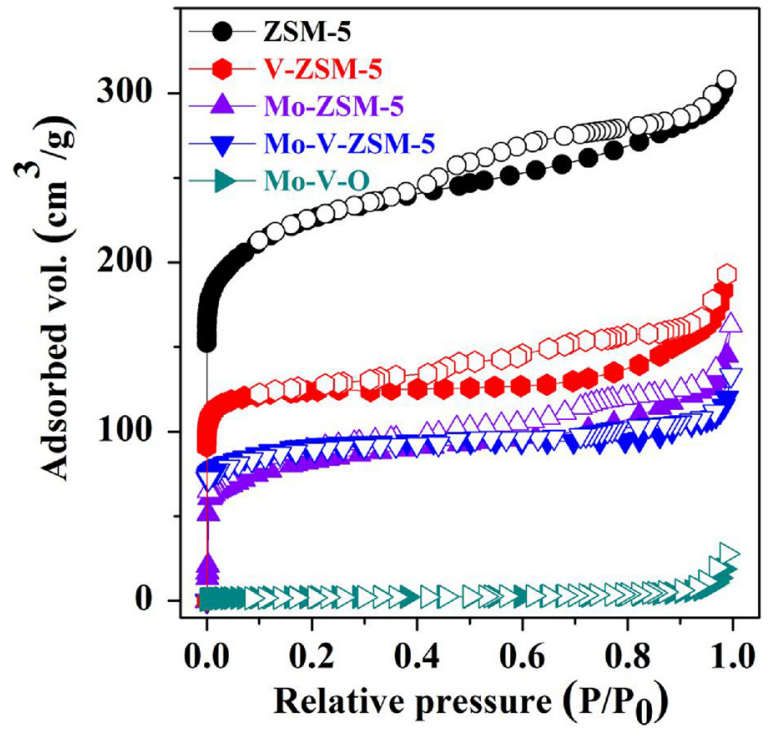

Fig. 3. Nitrogen adsorption-desorption isotherms after calcination.

framework aluminium atoms in octahedral coordination were present in the region from 10 to $-10 \mathrm{ppm}$. In the case of the parent ZSM-5 catalyst, the vast majority of the aluminium atoms are inserted in the zeolite framework. However, due to the release of large amounts of $\mathrm{NH}_{3}$ at temperatures up to $400{ }^{\circ} \mathrm{C}$, resulting from decomposition of the Mo and $\mathrm{V}$ ammonium precursors, extra-framework aluminium is formed as the zeolite structure becomes partially disrupted. This was reflected in the micropore volume of the zeolites, as measured using nitrogen adsorption-desorption isotherms (Fig. 3), which decreased from $0.33 \mathrm{~cm}^{3}$ / $\mathrm{g}$ (ZSM-5) to $0.11 \mathrm{~cm}^{3} / \mathrm{g}$ (Mo-V-ZSM-5) (Table 2). In addition, the external specific area was affected by the impregnation with the Mo and $\mathrm{V}$ precursors. The Mo-V-ZSM-5 sample presented the highest external specific area and the lowest micropore volume, which was related to the fact that this sample had the highest disorder of the molybdenumvanadium crystal structure, as revealed by the XRD analyses (Table 1).

The X-ray absorption spectra for the vanadium and molybdenum K- 
Table 2

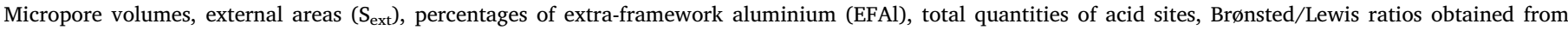
pyridine chemisorption, and $\mathrm{H}_{2}$ consumption determined by TPR, for the different materials.

\begin{tabular}{|c|c|c|c|c|c|c|c|c|}
\hline Catalyst & Micropore vol. $\left(\mathrm{cm}^{3} / \mathrm{g}\right)$ & $\mathrm{S}_{\text {ext }}\left(\mathrm{m}^{2} / \mathrm{g}\right)$ & $\begin{array}{l}\text { Acid sites } \\
\left(\mu \mathrm{mol} \mathrm{NH} \mathrm{N}_{3} / \mathrm{g}\right)\end{array}$ & $\mathrm{h} / \mathrm{l}^{\mathrm{a}}$ & $\begin{array}{l}\text { Brønsted/Lewis } \\
\text { molar ratio }^{\text {b }}\end{array}$ & $\begin{array}{l}\text { Brønsted/Lewis } \\
\text { molar ratio }\end{array}$ & $\operatorname{EFAl}(\%)^{\mathrm{d}}$ & $\begin{array}{l}\mathrm{H}_{2} \\
\text { (mol/g.min) }\end{array}$ \\
\hline ZSM-5 & 0.33 & 87 & 349 & 5.0 & 4.6 & 7.0 & 1.0 & $\ldots$ \\
\hline V-ZSM-5 & 0.16 & 52 & 489 & 0.8 & 3.5 & 7.8 & 5.5 & $6.3 \times 10^{-4}$ \\
\hline Mo-ZSM-5 & 0.07 & 139 & 325 & 0.2 & 3.4 & 6.0 & 8.0 & $1.4 \times 10^{-4}$ \\
\hline Mo-V-ZSM-5 & 0.11 & 77 & 417 & 0.5 & 2.6 & 4.0 & 15.0 & $9.4 \times 10^{-4}$ \\
\hline Mo-V-O & 0.0 & 3 & $510(83)^{\mathrm{e}}$ & 1.4 & 1.0 & $\ldots$ & $\ldots$ & \\
\hline
\end{tabular}

a Ratio between high temperature (h) and low temperature (l) peaks obtained from deconvolution of the $\mathrm{NH}_{3}-\mathrm{TPD}$ results.

b Determined by pyridine chemisorption degassing at $150{ }^{\circ} \mathrm{C}$.

c Pyridine chemisorption degasssing at $300^{\circ} \mathrm{C}$.

d Percentage of extra-framework aluminium (EFAl) determined by deconvolution of the ${ }^{27} \mathrm{Al}$ NMR spectrum.

e The quantity of acid sites in the spent catalyst is indicated within parentheses.
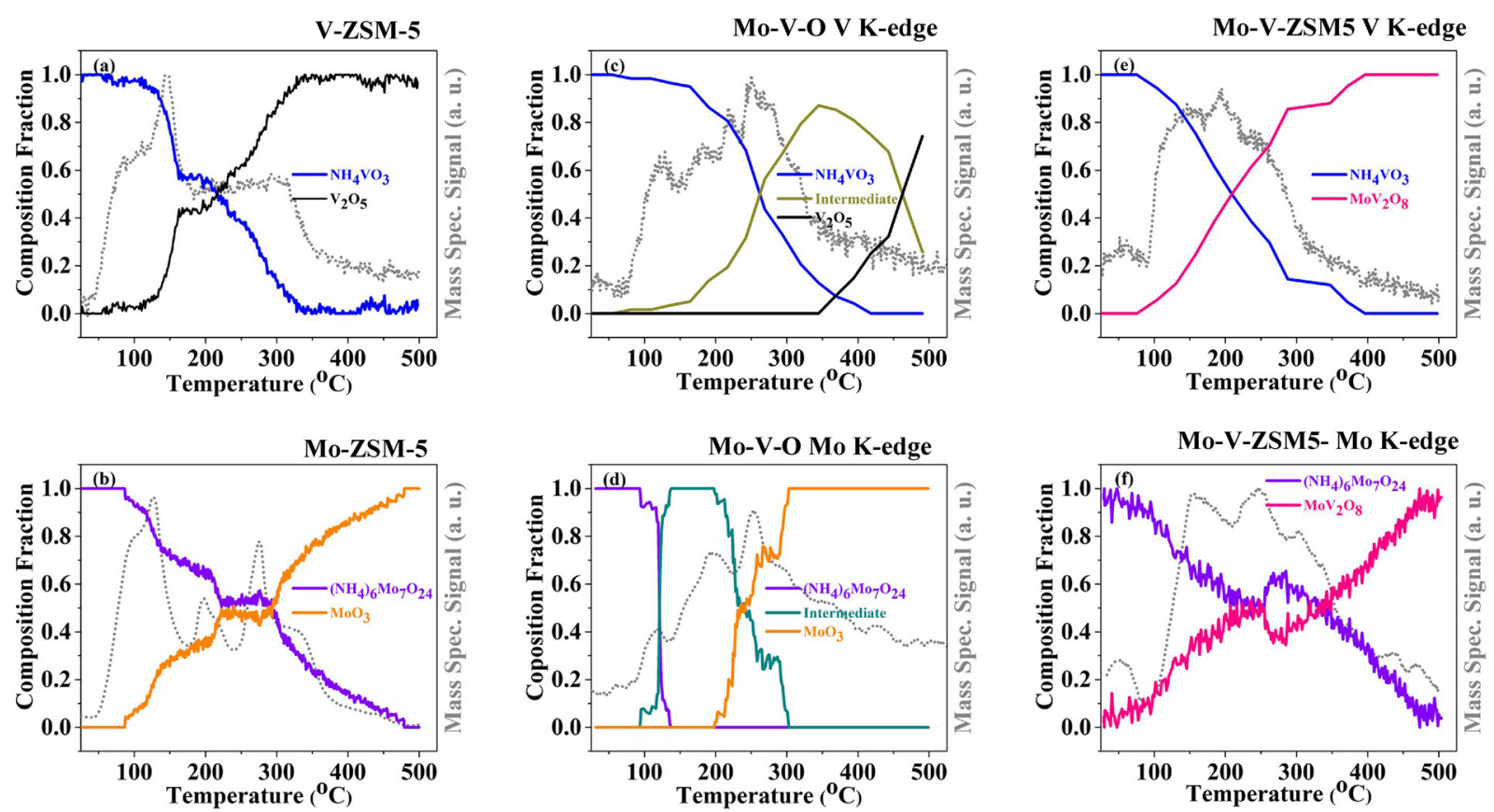

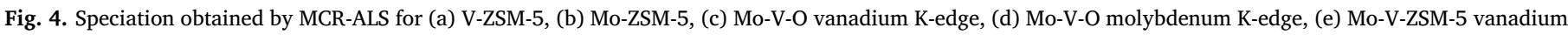

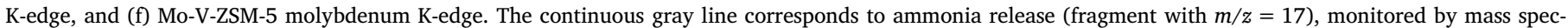
trometry.

edges obtained during the heat treatment of the samples are shown in Figs. S1-S6 (Supplementary Information). Fig. 4 shows the corresponding speciations obtained by MCR-ALS. The ZSM-5 zeolite impregnated with the vanadium salt (V-ZSM-5, Fig. 4a) was transformed into the final phase identified as $\mathrm{V}_{2} \mathrm{O}_{5}$ (Fig. S7) in a stepwise process, with an accelerated transformation at around $130{ }^{\circ} \mathrm{C}$, followed by a plateau between 150 and $200^{\circ} \mathrm{C}$, and a second acceleration at $200^{\circ} \mathrm{C}$. The transformation was complete at around $350{ }^{\circ} \mathrm{C}$. Similarly, the zeolite treated with the molybdenum salt (Mo-ZSM-5, Fig. 4b) presented a decomposition mechanism characterized by the direct stepwise transformation of the molybdenum salt into $\mathrm{MoO}_{3}$ (Fig. S8). A plateau in the decomposition rate occurred between 200 and $300^{\circ} \mathrm{C}$, when about $50 \%$ of the molybdenum salt had been converted to $\mathrm{MoO}_{3}$. The stepwise behaviours found for the two monometallic salts impregnated on ZSM- 5 were in good agreement with the thermal decompositions of ammonium metavanadate and ammonium heptamolybdate observed by thermogravimetry, leading to the final formation of $\mathrm{V}_{2} \mathrm{O}_{5}$ [37] and $\mathrm{MoO}_{3}$ [38], respectively. The stepwise mass losses reported in the literature were ascribed to the formation of successive ammonium polyvanadate and ammonium polymolybdate species, which were not resolved here by MCR-ALS (except for the stepwise concentration profiles). The failure to isolate these intermediate phases using MCRALS could be attributed to the poor resolution of the XAS features obtained for the zeolite-supported precursors, as observed in Figs. S7 and S8.

A 2-step decomposition of bulk Mo-V-O during the calcination was evidenced from the speciation obtained by MCR-ALS (Fig. 4c and d), for both the Mo and V K-edges. The MCR-ALS components determined at both edges are shown in Fig. S9. At the V K-edge, the second MCR-ALS component reached a maximum concentration $(\sim 85 \%)$ at around $350^{\circ} \mathrm{C}$, before being converted into the third component (Fig. 4c). The shape of the XANES spectrum of the latter was close to that of $\mathrm{V}_{2} \mathrm{O}_{5}$, but nevertheless was not totally superimposable. Considering the phase identification performed for the bulk Mo-V-O catalyst, the third component could be attributed to a mixture of $\mathrm{V}_{2} \mathrm{O}_{5}$ and $\mathrm{MoV}_{2} \mathrm{O}_{8}$, while the second component was identified as $\mathrm{NH}_{4} \mathrm{Mo}_{4} \mathrm{VO}_{15}$. It is interesting to note that the energy positions of the rising edge of the second component $\left(\mathrm{E}_{1 / 2}\right.$ at half absorbance $\left.=5481.15 \mathrm{eV}\right)$ and the third component $\left(\mathrm{E}_{1 / 2}\right.$ at half absorbance $\left.=5481.7 \mathrm{eV}\right)$ [39] were consistent with vanadium in the +5 oxidation state, in agreement with the proposed phases. The Mo K-edge spectrum also indicated that the decomposition of bulk Mo-V-O during the calcination involved an intermediate species, 


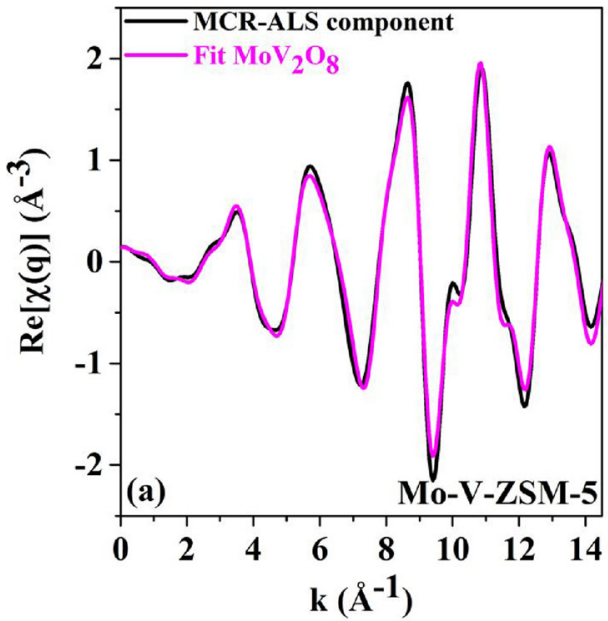

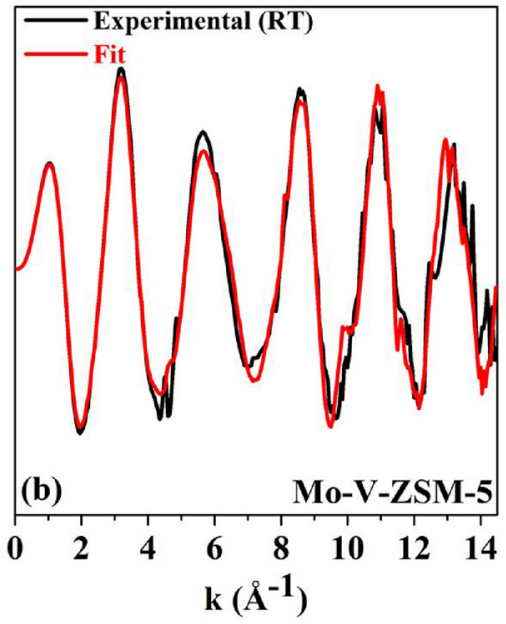

Fig. 5. (a) Mo K-edge EXAFS spectrum associated with the second MCR-ALS component determined in the Mo-V-ZSM-5 data set measured during calcination, and simulated EXAFS spectrum according to the crystallographic structure reported for $\mathrm{MoV}_{2} \mathrm{O}_{8}$. (b) Spectrum for the Mo-V-ZSM5 catalyst, together with the corresponding best linear combination fit obtained using the EXAFS spectra for the MCRALS component identified as $\mathrm{MoV}_{2} \mathrm{O}_{8}$ and for the $\mathrm{MoO}_{3}$ phase, recorded for Mo-ZSM-5 at RT. before the final transformation (Fig. 4d). According to previous work [27], the second intermediate determined by MCR-ALS could be interpreted as being a mixture of the $\mathrm{NH}_{4} \mathrm{Mo}_{4} \mathrm{VO}_{15}$ phase and $\left(\mathrm{NH}_{4}\right)_{2} \mathrm{Mo}_{4} \mathrm{O}_{13}$, while the third one was a mixture of $\mathrm{MoO}_{3}$ and $\mathrm{MoV}_{2} \mathrm{O}_{8}$.

As already observed for the monometallic phases impregnated in ZSM-5 (Fig. 4a and b), the data for both K-edges showed that the speciation during calcination of the Mo-V-ZSM-5 sample (Fig. 4e and f) was characterized by direct transformation of the initial phase into the final ones. The MCR-ALS components determined at both K-edges are presented in Fig. S10. Different to the monometallic and Mo-V-O bulk samples, which evolved towards $\mathrm{MoO}_{3}$ and $\mathrm{V}_{2} \mathrm{O}_{5}$ at the end of the heating ramp to $500^{\circ} \mathrm{C}$, the thermal decomposition of the Mo-V-ZSM-5 sample resulted in formation of the $\mathrm{MoV}_{2} \mathrm{O}_{8}$ species. For this catalyst, the Mo K-edge EXAFS spectrum of the MCR-ALS species extracted as the second component of the single-step transformation was successfully simulated considering the crystallographic structure of the mixed $\mathrm{MoV}_{2} \mathrm{O}_{8}$ oxide [40] (Fig. 5 and Table 3). As detected by the XRD Rietveld refinement, the $\mathrm{MoO}_{3}$ phase was also observed, but only after $2 \mathrm{~h}$ of isothermal treatment at $500{ }^{\circ} \mathrm{C}$. Linear combination fitting of the EXAFS signal recorded at the end of the isothermal treatment evidenced that $\sim 25 \%$ of $\mathrm{MoO}_{3}$ was mixed with the $\mathrm{MoV}_{2} \mathrm{O}_{8}$ (Fig. S11). The extraction of the XAS signal for $\mathrm{MoV}_{2} \mathrm{O}_{8}$ from the data set recorded during the heating of Mo-V-ZSM5 was an important result, because this signal could be used for approximate estimations of the proportions of the phases in both bimetallic catalysts after calcination. Table 4 and Fig. 5b provide the results of the linear combination fittings of the EXAFS spectra recorded at RT after calcination, using the MCR-ALS EXAFS signal characterizing $\mathrm{MoV}_{2} \mathrm{O}_{8}$, together with the EXAFS spectrum of Mo-ZSM5 after calcination, as well as the $\mathrm{MoO}_{3}$ signal. After calcination, the $\mathrm{MoV}_{2} \mathrm{O}_{8}$ phase composed $72 \%$ of the Mo-V-ZSM-5 catalyst, compared to $45 \%$ for Mo-V-O. From this in-depth characterization of the species formed during calcination, it was clearly evident that the dispersion of molybdenum and vanadium on the zeolite led to greater

\section{Table 3}

Structural parameters obtained from analysis of the MCR-ALS EXAFS spectrum for the species in the data set for Mo-V-ZSM- 5 measured during calcination. Coordination numbers were fixed at the values corresponding to the $\mathrm{MoV}_{2} \mathrm{O}_{8}$ phase.

\begin{tabular}{|c|c|c|c|c|}
\hline $\mathrm{N}$ & $\mathrm{R}(\AA)$ & $\sigma^{2}\left(\AA^{2}\right)\left(10^{-3}\right)$ & $\mathrm{E}_{0}(\mathrm{eV})$ & $\mathrm{R}_{\mathrm{F}}\left(10^{-3}\right)$ \\
\hline 10 & $1.70 \pm 0.01$ & $0.6 \pm 0.3$ & $-3.7 \pm 2.9$ & 9.1 \\
\hline 40 & $1.81 \pm 0.08$ & $46 \pm 9$ & & \\
\hline 10 & $2.42 \pm 0.02$ & $7 \pm 3$ & & \\
\hline 2 Mo & $3.57 \pm 0.02$ & $8 \pm 1$ & & \\
\hline $2 \mathrm{~V}$ & $3.54 \pm 0.02$ & $8 \pm 3$ & & \\
\hline
\end{tabular}

Table 4

Phase speciation for Mo phases determined by linear combination fitting of the RT EXAFS signal for the mixed $\mathrm{Mo}_{\mathrm{x}} \mathrm{V}_{\mathrm{y}} \mathrm{O}_{\mathrm{z}}$ oxide after calcination (range for the fit: 0 to $11.8 \AA^{-1}$ ).

\begin{tabular}{llll}
\hline Catalyst & $\mathrm{MoO}_{3}(\%)$ & $\mathrm{MoV}_{2} \mathrm{O}_{8}(\%)$ & $\mathrm{R}_{\mathrm{F}}$ \\
\hline Mo-V-ZSM-5 & 28 & 72 & 0.024597 \\
Mo-V-O (bulk) & 55 & 45 & 0.092107 \\
\hline
\end{tabular}

formation of the mixed $\mathrm{MoV}_{2} \mathrm{O}_{8}$ oxide, compared to the bulk Mo-V-O sample, by kinetically delaying the formation of monometallic oxides $\left(\mathrm{MoO}_{3}\right.$ or $\left.\mathrm{V}_{2} \mathrm{O}_{5}\right)$.

\subsection{Quantification and nature of acid sites}

The $\mathrm{NH}_{3}$-TPD curves for the pristine and impregnated zeolites are provided in Fig. 6a. The ZSM-5 sample presented a typical TPD curve profile for zeolites in acidic form. The curves showed two desorption peaks, denoted low and high temperature events ("l" and " $h$ ", respectively). The quantification of desorbed ammonia is presented in Table 2. The V-ZSM-5 sample showed a decrease in intensity and shift of the hpeak to lower temperatures, probably due to covering of the strong Brønsted acid sites by vanadium oxide species. Increased intensity of the l-peak was related to the increase in the quantity of Lewis acid sites, either by the creation of extra-framework aluminium sites (EFAl, Table 2) or by the contribution of dispersed vanadium oxide species. The Mo-ZSM-5 and Mo-V-ZSM5 samples showed the same behaviour, but the changes in the h-peak were intensified, due to the more severe dealumination of these samples after impregnation and heat treatment, as evidenced by the Al NMR results.

Although the $\mathrm{h} / \mathrm{l}$ peak intensity ratio provided an estimate of the change in the types of acid sites, a more suitable way to evaluate the Brønsted and Lewis sites in zeolite catalysts is by means of pyridine chemisorption. The nature and strength of the superficial acid sites were determined by FTIR of pyridine chemisorbed at $25^{\circ} \mathrm{C}$ and sequential outgassing at 150 and $300^{\circ} \mathrm{C}$. The FTIR spectra of all samples obtained after outgassing at $150{ }^{\circ} \mathrm{C}$ are shown in Fig. 6b. On ZSM-5 spectrum the split of the $1440-1460 \mathrm{~cm}^{-1}$ band in two overlapping peaks is observed, that could be assigned to pyridine adsorbed on strong Lewis acid sites due to $\mathrm{Al}$ (band at $1455 \mathrm{~cm}^{-1}$ ) and weaker acid sites $\left(1445 \mathrm{~cm}^{-1}\right)$ either terminal hydroxyl groups that do not protonate pyridine. The characteristic band at $1545 \mathrm{~cm}^{-1}$ due to pyridinium ion adsorbed on Brønsted acid sites is also appreciated. In the $1600 \mathrm{~cm}^{-1}$ region three bands can be distinguished at 1634, 1625 and $1612 \mathrm{~cm}^{-1}$ that arise from pyridine adsorbed on Brønsted, strong and weak Lewis acid sites, respectively. The impregnation of ZSM-5 zeolite with V 

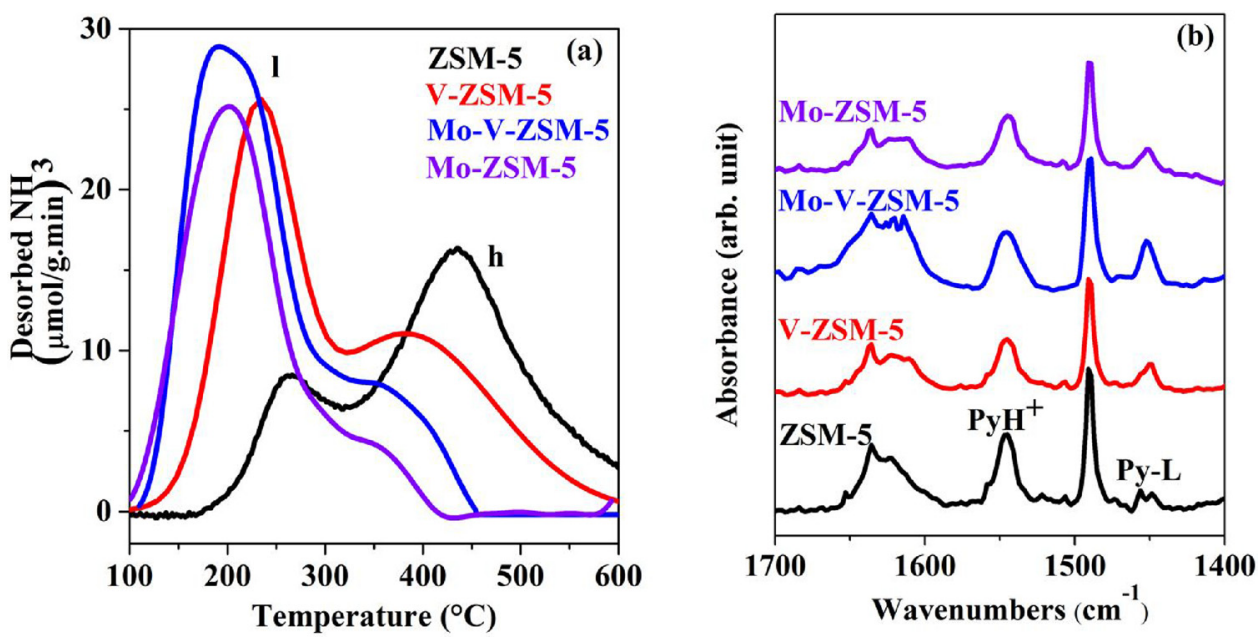

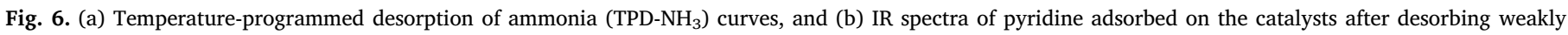
bonded species at $150{ }^{\circ} \mathrm{C}$, for the calcined samples.

generate new weaker acid sites as it was noted in $\mathrm{NH}_{3}$-TPD profile, which can be both Brønsted and Lewis nature [41-43]. On V-ZSM-5 new bands at $1450 \mathrm{~cm}^{-1}$, and $1608 \mathrm{~cm}^{-1}$ can be noticed. These bands have already been reported on similar material such as $\mathrm{V} / \mathrm{Al}_{2} \mathrm{O}_{3}, \mathrm{~V}$ / SiBEA, V/MCM41 [41-43] and have been attributed to new Lewis acid sites. The positions of these bands (at low wavenumber) indicate that the new Lewis acid sites are weaker than Lewis acid sites due to $\mathrm{Al}$ which is consistent with the results observed by $\mathrm{NH}_{3}$-TPD. According to Tielens and Dzwigaj, Lewis acid site is found to be a tetrahedral V site, whereas the Brønsted acid sites are penta-coordinated V sites having an $\mathrm{OH}$ group [44].

The spectrum of Mo-ZSM-5 shows an asymmetric band at 1450 $\mathrm{cm}^{-1}$ suggesting the presence of more than one type of Lewis acid site [45]. The same observation can be made in $1600 \mathrm{~cm}^{-1}$ region, where a broad band can be deconvoluted in at least three bands at $1637 \mathrm{~cm}^{-1}$ (Brønsted acid sites), $1622 \mathrm{~cm}^{-1}$ and $1610 \mathrm{~cm}^{-1}$ (Lewis sites of different type and strength). In addition to acid sites due to $\mathrm{Al}$, Lewis acidity may be due to generation of anion vacancies on molybdenum. Brønsted sites have been also reported on oxidized Molybdena-Alumina by Suarez et al. [45] that have been attributed to hydroxyl groups on alumina which are near molybdena clusters since they may be more acidic by inductive effects due to the difference in electronegativity. On Mo-V-ZSM-5 it can be observed all bands corresponding to acid sites, Brønsted and Lewis of different nature and strength.

The relative contribution of Brønsted and Lewis acid sites after evacuation of pyridine at 150 and $300{ }^{\circ} \mathrm{C}$ was obtained then by integration of the characteristics bands centred at $1540 \mathrm{~cm}^{-1}\left(\mathrm{PyH}^{+}\right)$and $1440-1460 \mathrm{~cm}^{-1}$ (Py-L).

After evacuation at $150^{\circ} \mathrm{C}$, the ZSM-5 sample showed the highest Brønsted/Lewis ratio (Table 2), while the V-ZSM-5 sample had a lower Brønsted/Lewis ratio in agreement with the $\mathrm{h} / \mathrm{l}$ ratio of ammonia TPD profile. The Mo-V-ZSM-5 sample showed the lowest Brønsted/Lewis ratio and the Mo-ZSM-5, despite the highest decrease in h-peak of the ammonia TPD, had a Brønsted/Lewis ratio of 3.4 due to the absence of vanadium atoms that significantly contribute to Lewis acid sites formation. The $\mathrm{B} / \mathrm{L}$ ratios increased with the evacuation temperature. After degassing at $300{ }^{\circ} \mathrm{C}$, ZSM-5 and V-ZSM-5 showed the highest Brønsted/Lewis ratios (7.0 and 7.8 respectively), followed by Mo-ZSM5 (6.0) indicating that Lewis acid sites generated by the impregnation of ZSM-5 with V or Mo are weak as suggested by the position of the IR bands in the $1600 \mathrm{~cm}^{-1}$ region. The increment in the $\mathrm{B} / \mathrm{L}$ ratio was lower on the Mo-V-ZSM-5 sample from 2.6 (for desorption temperature $\left.150{ }^{\circ} \mathrm{C}\right)$ to $4.0\left(300^{\circ} \mathrm{C}\right)$ which is probably due to sum of two effects: i) the covering of Brønsted acid sites of the parent zeolite by the Mo-V-O mixed oxide and ii) the severe dealumination suffered by this sample.

\subsection{Catalytic dehydration and oxidation of glycerol}

Fig. 7a groups all the results of the catalytic experiments performed with the different samples: the pristine ZSM-5 zeolite; the samples impregnated with vanadium, molybdenum, and vanadium-molybdenum precursors; and the bulk $\mathrm{Mo}_{\mathrm{x}} \mathrm{V}_{\mathrm{y}} \mathrm{O}_{\mathrm{z}}$ oxide. After $1 \mathrm{~h}$ under reaction conditions, the main product formed with the ZSM-5 zeolite was acrolein $(\sim 45 \%)$, as expected for a catalyst containing only acid sites. The Mo-ZSM- 5 sample showed decreased selectivity to acrolein (16\%), due to its further conversion to acrylic acid (10\%), while a slightly higher selectivity to acrylic acid $(18 \%)$ was achieved with the V-ZSM-5 sample.

In a previous study employing a series of bulk $\mathrm{Mo}_{\mathrm{x}} \mathrm{V}_{\mathrm{y}} \mathrm{O}_{\mathrm{z}}$ oxides [27], it was shown that use of a Mo/(Mo $+\mathrm{V})$ molar ratio of 0.6 resulted in the highest amount of $\mathrm{MoV}_{2} \mathrm{O}_{8}$. In the present work, the amount of the most active phase for oxidation of acrolein to acrylic acid, impregnated in the ZSM-5 zeolite, was $72 \mathrm{wt}$ \% (Table 4). The driving force of the redox mechanism involving the $\mathrm{MoV}_{2} \mathrm{O}_{8}$ phase is the formation of oxygen vacancies in the metal oxides and the subsequent reestablishment of the oxidized sites $\left(\mathrm{V}^{5+} \rightarrow \mathrm{V}^{4+} \rightarrow \mathrm{V}^{5+}\right)$. Isolated $\mathrm{V}_{2} \mathrm{O}_{5}$ and $\mathrm{MoO}_{3}$ are active catalysts, but production of the $\mathrm{MoV}_{2} \mathrm{O}_{8}$ mixed oxide led to greater formation of vacancies around the vanadium atoms, by means of rapid changes in the oxidation state of the vanadium atoms, known as the Mars-Van Krevelen mechanism, resulting in superior activity. Furthermore, the simple $\mathrm{V}_{2} \mathrm{O}_{5}$ and $\mathrm{MoO}_{3}$ oxides impregnated in ZSM-5 zeolites present low selectivity to liquid products (around 30\%) and high potential for the complete oxidation of glycerol with production of undesirable products such as $\mathrm{CO}$ and $\mathrm{CO}_{2}$. During $1 \mathrm{~h}$ under reaction conditions, the bulk $\mathrm{Mo}_{\mathrm{x}} \mathrm{V}_{\mathrm{y}} \mathrm{O}_{\mathrm{z}}$ showed selectivity to acrylic acid of $32 \%$, with glycerol conversion close to $100 \%$ (Fig. 7a). However, the process of deactivation of the bulk catalyst was very fast (Fig. 7b), decreasing the selectivities to both acrylic acid and condensable products, due to phase transformation of $\mathrm{MoV}_{2} \mathrm{O}_{8}$ to $\mathrm{Mo}_{4} \mathrm{~V}_{6} \mathrm{O}_{25}$ during the course of the reaction [27]. In general, the low surface area of unsupported bulk oxides employed in redox reactions hinders the dynamics of re-oxidation, hence favouring catalyst deactivation.

The pristine ZSM-5 acid catalyst showed $31 \%$ deactivation during the same reaction period (Fig. $7 \mathrm{c}$ ), but the reason for this was the formation of coke, which occurred preferentially on the strong Brønsted acid sites of the zeolite and blocked the access of glycerol to the inner 
- Conversion $\square$ Acetaldehyde $12 \pi$ Acrolein

$\checkmark$ Selec. condensable products $\square$ Acetic Acid
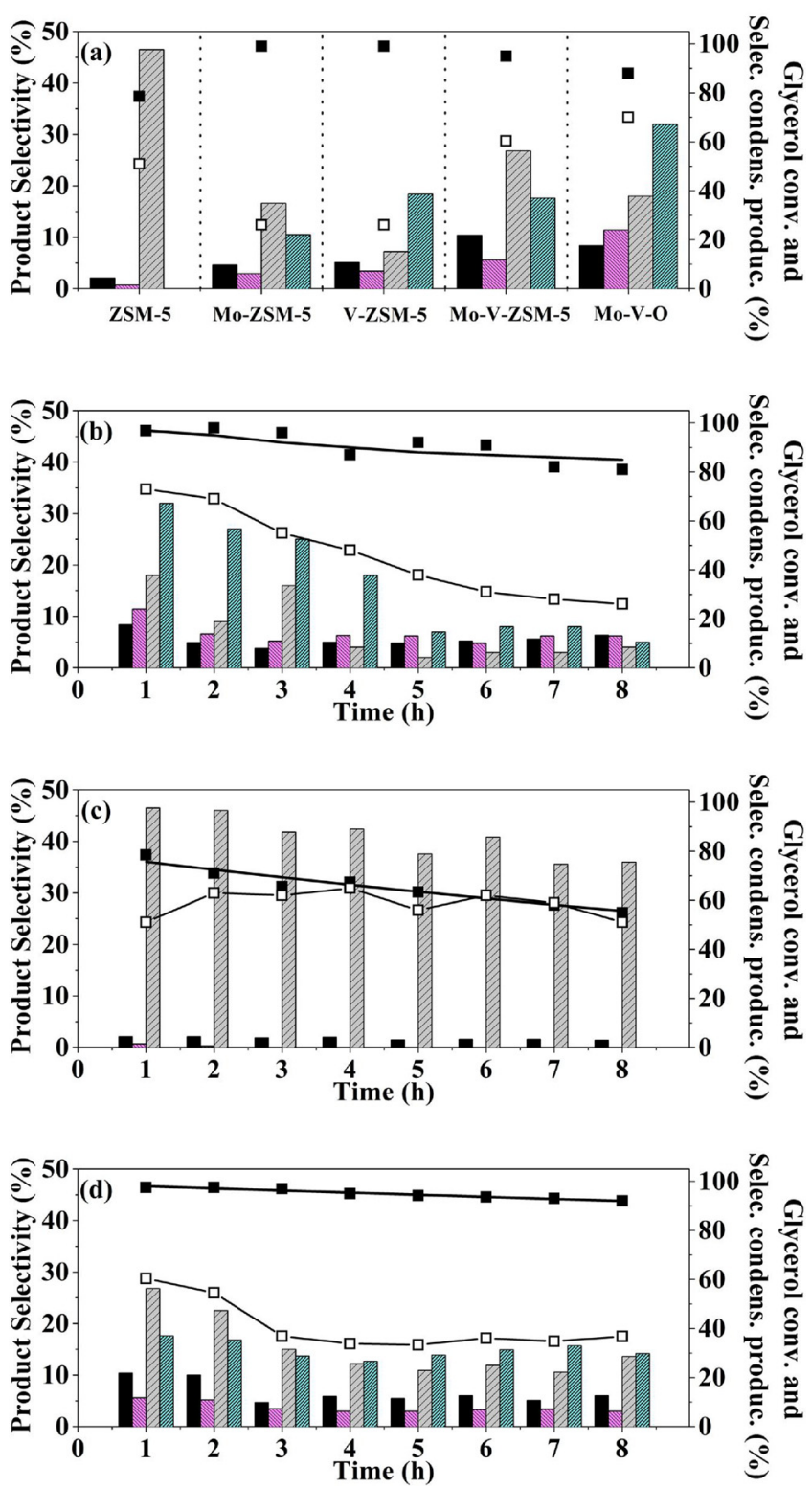

Fig. 7. (a) Glycerol conversion and product selectivity after $1 \mathrm{~h}$ of oxidative dehydration for the reference ZSM-5 zeolite, zeolites impregnated with $\mathrm{V}_{2} \mathrm{O}_{5}$, $\mathrm{MoO}_{3}$, and $\mathrm{Mo}_{\mathrm{x}} \mathrm{V}_{\mathrm{y}} \mathrm{O}_{\mathrm{z}}$, and bulk $\mathrm{Mo}_{\mathrm{x}} \mathrm{V}_{\mathrm{y}} \mathrm{O}_{\mathrm{z}}$. Stability test results for (b) the parent $\mathrm{H}^{+}$-ZSM-5, (c) Mo-V-ZSM-5, and (d) bulk $\mathrm{Mo}_{\mathrm{x}} \mathrm{V}_{\mathrm{y}} \mathrm{O}_{\mathrm{z}}$. The selectivity to condensable products corresponds to the total selectivity to all condensed products (acrolein, acrylic acid, acetaldehyde, and acetic acid).

active sites. On the other hand, the multifunctional Mo-V-ZSM-5 catalyst presented the most constant selectivity to both acrylic acid (18\%) and acrolein (28\%) during the $8 \mathrm{~h}$ of reaction (Fig. $7 \mathrm{~d}$ ). The supported $\mathrm{MoV}_{2} \mathrm{O}_{8}$ active phase present in the Mo-V-ZSM-5 sample led to an improved redox cycle and, consequently, to the formation of acrylic acid. In assessment of the redox properties of the catalysts, $\mathrm{H}_{2}$-TPR measurements (Fig. S12) revealed improved reducibility of the Mo-V-ZSM-5 catalyst, compared to the simple oxides. Moreover, as revealed previously by the acidity measurements, the most acidic Brønsted sites of the zeolite were suppressed after impregnation with the Mo and V precursors. Consequently, the presence of Brønsted acid sites of moderate strength helped to increase the selectivity to acrolein, at the same time that coke formation was diminished. The combination of these two properties enhanced the redox and acidic performance of the Mo-V-ZSM-5 catalyst, which helped to increase the selectivity to liquid products to almost $60 \%$ (Fig. $7 \mathrm{a}$ ), despite minor deactivation. These features were a consequence of the dispersion of molybdenum and vanadium mixed oxides on the Mo-V-ZSM- 5 sample, which hindered phase transition from $\mathrm{MoV}_{2} \mathrm{O}_{8}$ to $\mathrm{Mo}_{4} \mathrm{~V}_{6} \mathrm{O}_{25}$.

The specific rate of formation of acrylic acid (in (mol acrylic acid). $(\mathrm{mol} \mathrm{Mo}+\mathrm{V} \text { sites })^{-1} \cdot \mathrm{h}^{-1}$ ) was estimated. For $1 \mathrm{~h}$ of reaction, the MoV-ZSM-5 catalyst showed a specific rate of acrylic acid formation that was $\sim 11$ times higher than for the bulk $\mathrm{Mo}_{\mathrm{x}} \mathrm{V}_{\mathrm{y}} \mathrm{O}_{\mathrm{z}}$ catalyst, with values of $9.2 \times 10^{-3}$ and $0.8 \times 10^{-3}$, respectively. In other words, the productivity of acrylic acid, according to the quantity of molybdenum and vanadium active sites, was higher for the supported Mo-V-ZSM-5 catalyst.

Other temperatures and $\mathrm{O}_{2}$ concentrations were used in an attempt to improve the catalytic activity for glycerol conversion and the selectivity to acrylic acid. For the Mo-V-O sample, decrease of the temperature to $300^{\circ} \mathrm{C}$ reduced the formation of acrylic acid to less than $10 \%$ (Fig. S13). Similarly, at $350{ }^{\circ} \mathrm{C}$, increase of the $\mathrm{O}_{2}$ concentration was not advantageous for acrylic acid selectivity of the Mo-V-O and MoV-ZSM-5 samples, possibly due to an increase in the oxidation of products to $\mathrm{CO}_{\mathrm{X}}$.

\subsection{Analysis of the spent catalysts}

The thermogravimetric and differential thermal analyses of the spent catalysts (Fig. 8a and b, respectively) showed very distinct profiles indicative of a combination of the decomposition of coke and the oxidation of partially reduced active sites (such as $\mathrm{V}_{2} \mathrm{O}_{\mathrm{x}}+\mathrm{O}_{2} \rightarrow \mathrm{V}_{2} \mathrm{O}_{5}$ ). Considering the pristine ZSM-5 zeolite, the weight loss in the temperature range from 400 to $500{ }^{\circ} \mathrm{C}$, together with the corresponding broad signal in the DTA measurement, were previously ascribed to the decomposition of two families of coke, namely polyethers (decomposition below $510{ }^{\circ} \mathrm{C}$ ) and polyaromatic compounds (decomposition above $540^{\circ} \mathrm{C}$ ) [26]. The polyethers are formed on the external surfaces of the zeolites, covering the active sites and causing their deactivation. The polyaromatics, on the other hand, can block the zeolite pores and considerably impair the movement of molecules towards the inner active sites. The ZSM-5 zeolite showed the highest quantity of coke $(11.5 \%)$ and the broadest DTA profile, while the Mo-ZSM-5, V-ZSM-5, and Mo-V-ZSM-5 catalysts showed coke contents of 9.4, 8.4 and 8.4\%, respectively. These low values could be attributed to the decreased number of strong Brønsted acid sites, as discussed above. The DTA curves for the latter samples presented narrower exothermic peaks at around $540{ }^{\circ} \mathrm{C}$, compared to the ZSM-5 sample, revealing the multiple benefits of the impregnation of $\mathrm{V}$ and Mo species, which not only converted acrolein to acrylic acid, but also minimized the formation of coke and assisted its oxidation. Finally, no coke was observed on the bulk $\mathrm{Mo}_{\mathrm{x}} \mathrm{V}_{\mathrm{y}} \mathrm{O}_{\mathrm{z}}$ catalyst; instead, the sample showed a weight gain due to the oxidation of residual $\mathrm{V}^{4+}$.

\section{Conclusions}

In this study, mixed $\mathrm{Mo}_{\mathrm{x}} \mathrm{V}_{\mathrm{y}} \mathrm{O}_{\mathrm{z}}$ oxides were impregnated on an acidic ZSM-5 zeolite, producing a multifunctional catalyst used in the coupled dehydration-oxidation of glycerol to acrylic acid. The evolution of the phases during activation of the catalyst precursors was monitored using synchrotron $\mathrm{X}$-ray diffraction analyses, but crystalline $\mathrm{Mo}_{\mathrm{x}} \mathrm{V}_{\mathrm{y}} \mathrm{O}_{\mathrm{z}}$ oxides were not detected, due to their high degree of dispersion. However, use of X-ray absorption spectroscopy performed simultaneously at the Mo and $\mathrm{V}$ K-edges confirmed formation of the $\mathrm{MoV}_{2} \mathrm{O}_{8}$ active phase as the main phase supported on the zeolite. The results of catalytic tests 

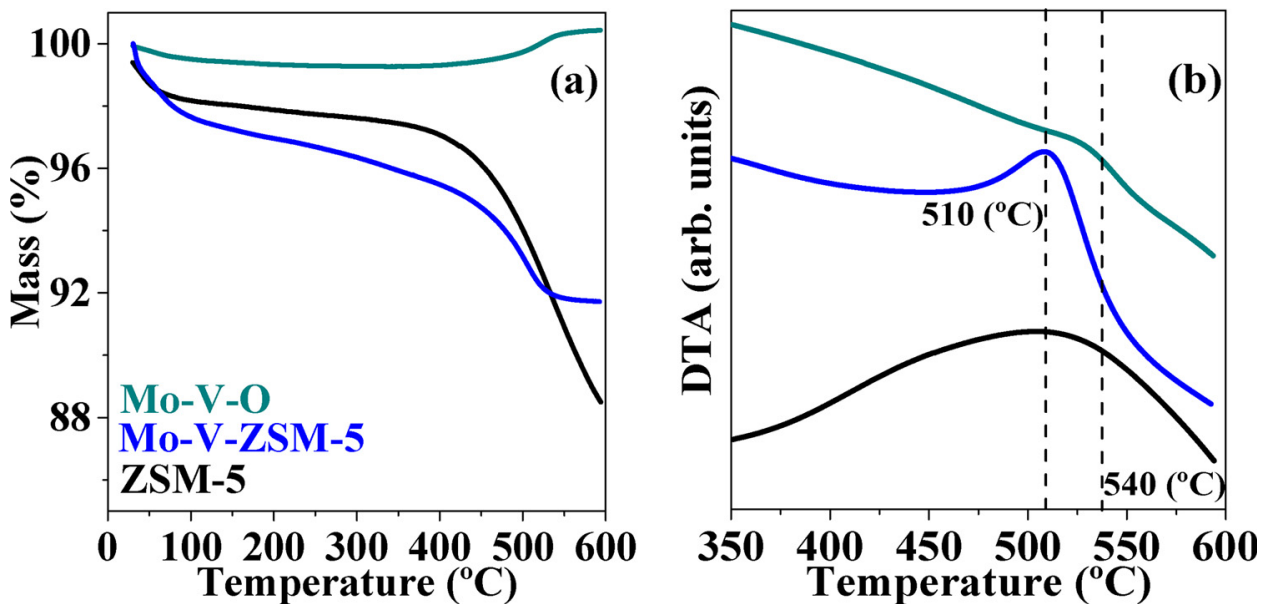

Fig. 8. (a) Thermogravimetric analyses and (b) differential thermal analyses of the spent catalysts.

indicated that use of the $\mathrm{MoV}_{2} \mathrm{O}_{8} / \mathrm{ZSM}-5$ catalyst led to high formation of acrylic acid, with very low coke deposition and maintenance of longterm stability. The stability of the catalyst could be attributed to the chemical environment of the highly dispersed and supported $\mathrm{MoV}_{2} \mathrm{O}_{8}$ mixed oxide, which did not undergo phase transition to the less active $\mathrm{Mo}_{4} \mathrm{~V}_{6} \mathrm{O}_{25}$ phase, as well as to the proximity of the acid and redox active sites, which enabled continuous oxidation of undesired monomeric coke residues, prior to their polymerization.

\section{Acknowledgements}

This work was supported by the Brazilian agencies CNPq (grants \#473346/2012-5 and \#401679/2013-6) and FAPESP (grants \#2016/ 10597-2, \#2013/10204-2, and \#2013/50023-7), and by a public grant overseen by the French National Research Agency (ANR) as a part of the "Investissements d'Avenir" (ref: ANR-10-EQPX-45) provided for the building of the ROCK beamline. The authors also thank the Brazilian Synchrotron Light Laboratory (LNLS) in Campinas for use of the XPD beamline (proposals XPD-17839 and XPD-20150135), Synchrotron Soleil for beamtime at the ROCK beamline (proposal \#20150939), and Consejo Nacional de Investigaciones Científicas y Técnicas (CONICET).

\section{Appendix A. Supplementary data}

Supplementary material related to this article can be found, in the online version, at doi: https://doi.org/10.1016/j.mcat.2018.07.029.

\section{References}

[1] B. Katryniok, S. Paul, F. Dumeignil, ACS Catal. 3 (2013) 1819-1834.

[2] D. Sun, Y. Yamada, S. Sato, W. Ueda, Green Chem. 19 (2017) 3186-3213.

[3] C.A.G. Quispe, C.J.R. Coronado, J.A. Carvalho, Energy Rev. 27 (2013) 475-493.

[4] H.P. Decolatti, B.O. Dalla Costa, C.A. Querini, Microporous Mesoporous Mater. 204 (2015) 180-189.

[5] L. Shen, H. Yin, A. Wang, X. Lu, C. Zhang, Chem. Eng. J. 244 (2014) 168-177.

[6] J. Deleplanque, J.L. Dubois, J.F. Devaux, W. Ueda, Catal. Today 157 (2010) 351-358.

[7] L.F. Rasteiro, L.H. Vieira, L.G. Possato, S.H. Pulcinelli, C.V. Santilli, L. Martins, Catal. Today 296 (2017) 10-18.

[8] L.H. Vieira, L.G. Possato, T.F. Chaves, S.H. Pulcinelli, C.V. Santilli, L. Martins, Mol. Catal. (2017), https://doi.org/10.1016/j.mcat.2017.11.027 in press.

[9] L.G. Possato, R.N. Diniz, T. Garetto, S.H. Pulcinelli, C.V. Santilli, L. Martins, J. Catal. 300 (2013) 102-112.

[10] G.S. Foo, D. Wei, D.S. Sholl, C. Sievers, ACS Catal. 4 (2014) 3180-3192.

[11] Z. Wang, L. Wang, Y. Jiang, M. Hunger, J. Huang, ACS Catal. 4 (2014) 1144-1147.

[12] M. Dolores Soriano, P. Concepcion, J.M. Lopez Nieto, F. Cavani, S. Guidetti,
C. Trevisanut, Green Chem. 13 (2011) 2954-2962.

[13] C.F.M. Pestana, A.C.O. Guerra, G.B. Ferreira, C.C. Turci, C.J.A. Mota, J. Braz. Chem. Soc. 24 (2013) 100-105.

[14] A.S. Paula, L.G. Possato, D.R. Ratero, K. Keinan-Adamsky, R.R. Soares, G. Goobes, L. Martins, J.G. Nery, Microporous Mesoporous Mater. 232 (2016) 151-160.

[15] K. Omata, K. Matsumoto, T. Murayama, W. Ueda, Chem. Lett. 43 (2014) 435-437.

[16] F. Wang, J.-L. Dubois, W. Ueda, J. Catal. 268 (2009) 260-267.

[17] W. Ueda, D. Vitry, T. Kato, N. Watanabe, Y. Endo, Res. Chem. Intermed. 32 (2006) $217-233$.

[18] A. Chieregato, J.M. Lopez Nieto, F. Cavani, Coord. Chem. Rev. 15 (2015) 3-23.

[19] S. Lopez-Pedrajas, R. Estevez, J. Schnee, E.M. Gaigneaux, D. Luna, F.M. Bautista, Mol. Catal. 455 (2018) 68-77.

[20] A. Chieregato, F. Basile, P. Concepcion, S. Guidetti, G. Liosi, M. Dolores Soriano, C. Trevisanut, F. Cavani, J.M. Lopez, Nieto, Catal. Today 197 (2012) 58-65.

[21] A. Chieregato, M.D. Soriano, E. Garcia-Gonzalez, G. Puglia, F. Basile, P. Concepcion, C. Bandinelli, J.M. Lopez Nieto, F. Cavani, ChemSusChem 8 (2015) 398-406.

[22] A. Chieregato, C. Bandinelli, P. Concepcion, M.D. Soriano, F. Puzzo, F. Basile, F. Cavani, J.M. Lopez, Nieto, ChemSusChem 10 (2017) 234-244.

[23] F. Wang, J. Xu, J.-L. Dubois, W. Ueda, ChemSusChem 3 (2010) 1383-1389.

[24] L.G. Possato, T.F. Chaves, W.H. Cassinelli, S.H. Pulcinelli, C.V. Santilli, L. Martins, Catal. Today 289 (2017) 20-28.

[25] K. Omata, K. Matsumoto, T. Murayama, W. Ueda, Catal. Today 259 (2016) 205-212.

[26] L.G. Possato, W.H. Cassinelli, T. Garetto, S.H. Pulcinelli, C.V. Santilli, L. Martins, Appl. Catal. A Gen. 492 (2015) 243-251.

[27] L.G. Possato, W.H. Cassinelli, C.I. Meyer, T. Garetto, S.H. Pulcinelli, C.V. Santilli, L. Martins, Appl. Catal. A Gen. 532 (2017) 1-11.

[28] H. Canova, A. Fontoura, R.T. Neuenschwander, B. Diaz, C.B. Rodella, J. Phys. Conf. Ser., IOP Publishing, 493 n.d.: p. 12004.

[29] V. Briois, C. La Fontaine, S. Belin, L. Barthe, T. Moreno, V. Pinty, A. Carcy, R. Girardot, E. Fonda, J. Phys. Conf. Ser. 712 (2016) 012149.

[30] J. Hong, E. Marceau, A.Y. Khodakov, L. Gaberová, A. Griboval-Constant, J.S. Girardon, C. La Fontaine, V. Briois, ACS Catal. 5 (2015) 1273-1282.

[31] W.H. Cassinelli, L. Martins, A.R. Passos, S.H. Pulcinelli, C.V. Santilli, A. Rochet, V. Briois, Catal. Today 229 (2014) 114-122.

[32] A. Rochet, B. Baubet, V. Moizan, C. Pichon, V. Briois, Comptes Rendus Chim. 19 (2016) 1337-1351.

[33] M. Staniuk, O. Hirsch, N. Kranzlin, R. Bohlen, W. Van Beek, P.M. Abdala, D. Koziej, Chem. Mater. 26 (2014) 2086-2094.

[34] B. Ravel, M. Newville, J. Synchrotron Radiat. 12 (2005) 537-541.

[35] L. Kihlborg, Ark. Kemi. 21 (1963) 357-364.

[36] C.A. Emeis, J. Catal. 141 (1993) 347-354.

[37] M. Askar, B. Girgis, M. Khilla, J. Therm. Anal. Calorim. 35 (1989) 1315-1324.

[38] J. Wienold, R.E. Jentoft, T. Ressler, Eur. J. Inorg. Chem. (2003) 1158-1171.

[39] J. Besnardiere, X. Petrissans, F. Ribot, V. Briois, C. Surcin, M. Morcrette, V. Buissette, T. Le Mercier, S. Cassaignon, D. Portehault, Inorg. Chem. 55 (2016) 11502-11512.

[40] P. Mahe-Pailleret, Rev. Chim. Miner. 7 (1970) 807-846.

[41] S. Lim, G.L. Haller, Appl. Catal. A Gen. 188 (1999) 277-286.

[42] M. Trejda, M. Ziolek, Y. Millot, K. Chalupka, M. Che, S. Dzwigaj, J. Catal. 281 (2011) 169-176.

[43] P. Concepción, M.T. Navarro, T. Blasco, J.M.L. Nieto, B. Panzacchi, F. Rey, Catal. Today 96 (2004) 179-186.

[44] F. Tielens, S. Dzwigaj, Catal. Today 152 (2010) 66-69.

[45] W. Suarez, J.A. Dumesic, C.G. Hill, J. Catal. 94 (1985) 408-421. 